\title{
Enrico Tullio Liebman e a Processualística Brasileira ${ }^{(*)}$
}

\author{
Luís Eulálio de Bueno Vidigal (**)
}

\begin{abstract}
RESUMO: Enrico Tullio Liebman "estrela de primeira grandeza" no firmamento das letras jurídicas italianas foi o maior processualista do universo das línguas românicas, a começar pela pesquisa histórica que descreve o instituto, a partir da "ordo judiciorum privatorum"; passa à "extraordinária cognitio" e recorda as "interrogationes in jure". Prossegue pelo direito intermédio e ao procedimento "per positiones", demonstrando, já a esse tempo original e profundo, que o trabalho dos glosadores teve singular influência na evolução dos institutos jurídicos. Declara-se contra a livre arbitragem, que considera violadora do princípio da unidade e exclusividade da jurisdição estatal. Conclui em seus estudos pela nulidade do pacto "solve e repete". Foi contratado Liebman por Sebastiāo Soares de Faria, em 1940, para ser Professor da Faculdade de Direito, sendo aqui recebido de braços abertos. Em setembro de 1961, já de volta à Itália, lá acompanhava a evolução sócio-política do País, considerando o regime parlamentarista aqui implantado no Governo Goulart na Constituição daquele ano "semelhante à tomada da Bastilha, na Europa" Em 1942 é um dos diretores da Rivista de Diritto Processuale. O jurista italiano morreu em setembro de 1986 em Milão.
\end{abstract}

\section{ENRICO TULLIO LIEBMAN ET LA SCIENCE BRÉSILIENNE DU PROCẼS $(*)$}

\begin{abstract}
RÉSUMÉ: "estrela de primeira grandeza" dans le domaine des Sciences Juridiques italiennes, Enrico Tullio Liebman fut le plus notable professeur de procès des langues romaines, à commencer par la recherche historique que l'institut décrit, depuis "ordo judiciorum privatorum", passant par "extraordinária cognitio" et rappelant les "interrogationes in jure" II poursuit par le droit intermédiaire et par la procedure "per positiones", prouvant en ce temps que le travail des glossateurs eut une singulière influence sur l'évolution des instituts juridiques. Il déclare être contre le libre arbitre, qu'il considère un facteur violateur de l'unité et de l'exclusivité de la juridiction étatistc. A près étude, il conclut être pour la nulité du pacte "solve e repete". En 1940, Sebastiāo Soares de Faria a engagé, tant que Professeur de la Faculté de Droit, Liebman qui fut reçu à bras ouverts. De retour en Italie, en septembre 1961, il accompagna l'évolution socio-politique du pays, prenant en considération le régime parlementaire ici introduit, durant le Gouvernement Goulart et le compara même "à la prise de la Bastille, en Europe". En 1942 il est un des directeurs de Rivista de Diritto Processuale. Lc juriste italien est décédé en septembre 1986 à Milan.
\end{abstract}

Em 1936, obedecendo a vocação para o magistério que vinha desde os tempos ginasiais, resolvi prestar concurso à cátedra nesta escola. O livro que, por escolha feita quase ao acaso, caiu em minhas mãos, foi, para felicidade minha, "Instituições", de Giuseppe Chiovenda, em segunda edição. A esse tem-

** Alocução pronunciada na Faculdade de Direito da Universidade de São Paulo em nurìenagen a Enrico Tullio Liebman, falecido em Milão, aos 8 de setembro de 1986.

** () autor É Professor Emérito da Faculdade de Direito da Universidade de São Paulo. 
po, o grande mestre que, desde uma preleção magistral, feita em 1903, "L'azione nel sistema dei diritti", era chefe incontestável de uma nova escola, começou a repartir com Francesco Carnelutti a glória da orientação dos estudiosos de direito processual. Ao lado de um e outro, fiel ao primeiro mas reverente ao segundo, Piero Calamandrei, fino espírito de jurista e literato, publicava ensaios brilhantes e originais, que levaram o governo italiano a confiar-lhe a elaboração do Projeto que se converteu no Código de Processo Civil. Para mim, foi um deslumbramento. Jamais imaginara que a ciência do processo encerrasse inúmeras questôes doutrinárias, tamanha multiplicidade de conceitos, tantas sutilezas, a desafiar a argúcia e a penetração dos mestres.

Confesso que, ao chegar Enrico Tullio Liebman a São Paulo em outubro de 1940, eu mal lhe ouvira o nome. Depois de uma longa carreira, encerrada há quase vinte anos, seja-me permitido referir essa omissão pecaminosa da juventude. Liebman já era estrela de primeira grandeza no firmamento das letras jurídicas italianas. Aos 23 anos, recém-formado, fora convidado, pela comissão promotora dos estudos em homenagem a Chiovenda (nada menos do que Antônio Castellari, Piero Calamandrei, Francesco Carnelutti, Enrico Redenti e Antônio Segni), para participar da coletânea de trabalhos jurídicos. O estudo que então elaborou, "Sul riconoscimento della domanda" já revela todas as excepcionais qualidades que, depois da morte dos três grandes que mencionei, o consagrariam como o maior processualista do universo das línguas românicas. A começar pela pesquisa histórica, Liebman descreve o instituto a partir da "ordo judiciorum privatorum"; passa à "extraordinária cognitio"; recorda as "interrogationes in jure"; prossegue pelo direito intermédio e ao procedimento "per positiones" e demonstra, já a esse tempo original e profundo, que o trabalho dos glosadores teve singular influência na evolução dos institutos jurídicos. Nem sempre compreendendo - ousou afirmar com intrepidez que merece ser honrada - o valor e o significado das fontes justinianeias, aplicavam-nas às novas necessidades nascidas da prática e revestiam de formas e nomes tradicionais institutos que com os antigos bem pouco tinham de comum. E conclui magistralmente: "Das duas formas de confissão conhecidas no direito romano, somente uma, aquela que só tem por objeto dos fatos, chegou ao direito intermédio. A outra, versando sobre o complexo do pedido adversário, perdeu toda a importância e pereceu. Pena que o Código brasileiro vigente não tivesse aproveitado essa lição. Nesse ensaio, que é de 1926, quando o mundo inteiro se debatia nas incertezas do conceito de ação, já advertia: "emprego o termo domanda com o sentido de "PRETESA" ou, melhor, segundo o termo alemão inevitável, de "ANSPRUCH".

Pouco depois, divergindo de Vittorio Scialoja, na época o maior dos juristas italianos, mais uma vez insistindo na distinção entre "pretesa" e ação, declara-se contra a livre arbitragem, que considera violadora do princípio da 
unidade e exclusividade da jurisdição estatal. Scialoja, fiel à regra da liberdade de contratar, admitia a validade do compromisso arbitral livre.

Em seguida, em ensaio absolutamente original, conclui pela nulidade do pacto "solve e repete", muito antes de aparecer a política de proteçāo da economia popular que viria a prescrevê-lo sem embargo do acordo das partes. A argumentação que então desenvolveu, no sentido da peculiaridade da proteção provisória do direito aparente, seria utilíssima no Brasil para a caracterização da singularidade da limitação da imutabilidade dos julgados em mandado de segurança.

Deve-se-lhe, ainda, antes de conquistar a cátedra universitária, a definição da natureza jurídica da decisão proferida na ação de delibação de sentenças estrangeiras como ato complexo constante de dois elementos fundamentais: a sentença estrangeira e a sentença de delibação.

Ao investir-se professor ordinário de Modena em 19 de janeiro de 1932 faz sua profissão de fé: "O processualista deve ser antes de tudo um jurista, pronto para os confrontos, as comparações, as interligações com todos os institutos jurídicos ainda que estranhos e aparentemente distantes de seu específico campo de atividade".

Contrariando a doutrina dominante, demonstrara pouco antes a improrrogabilidade da competência em processos de jurisdição voluntária e, sempre original e profundo, o caráter jurisdicional das decisões proferidas em processo de verificação de créditos na falência.

Em 1934, quando Carnelutti estava no auge de sua glória e autoridade, Liebman publica seu "Il titolo esecutivo riguardo ai terzi". Os termos da polêmica que então mantiveram mostram a que ponto Liebman subira no conceito dos grandes mestres da processualística italiana. Liebman entendia, como depois reafirmou no Brasil, que o título executivo é o ato jurídico que teria o efeito tipicamente constitutivo de determinar e tornar concreta e atuável a sanção executiva e dar vida portanto à ação execưtiva (da parte do credor) e à sujeição ou responsabilidade executiva (da parte do devedor). Ao revés, o velho mestre, insistindo no caráter francamente documental e probatório do título, se excedeu em excusas e concessões feitas a seu jovem opositor. Disse, por exemplo, com ironia que não escondia seu apreço e acatamento: "Pode ser conforme as nossas posições respectivas que Liebman não compreenda a utilidade de meu método, ao passo que eu, ao contrário, reconheça a utilidade do seu. $\mathrm{O}$ trabalho de assentamento, que ele está desenvolvendo com seus delicados instrumentos de jardineiro, dos torrões virados pelo avesso por minha rude aradura, a mim me parece louvável. Que ele, ao contrário, confunda meu esforço de arador com virtuosismo dialético, corresponde à antiga verdade contada por Virgilio: SIC VOS NON VOBIS FERTIS ARATRA BOVES". 
E, noutro passo, agora a propósito da coisa julgada: “O fato que um estudioso como Liebman, de temperamento e de escola tão diferentes se encontre (embora um pouco MALGRE LUI), sobre um ponto fundamental como aquele do julgado, a pensar como eu, é provavelmente um sinal de que nós dois tenhamos encontrado o caminho certo".

Foi por mero acaso que, já às vésperas de meu primeiro concurso, vim a conhecer a obra de Liebman. Tendo escrito monografia que versara sobre determinada forma de execução forçada, soube que um dos membros da banca examinadora que iria aprovar-me, o Prof. Oscar da Cunha, estranhara não ter eu nela desenvolvido o tema da "actio judicati" estreitamente ligado á história do processo de execução. Preparando-me para responder à objeção que deveria vir a ser feita, tive a surpresa e a felicidade de encontrar, descobrindo então a argúcia, a profundeza e a capacidade de investigação histórica de Liebman, seu livro magistral "Le opposizioni di merito nel processo di esecuzione". Procurando-o no Hotel Terminus, que então ainda se achava na Rua Brigadeiro Tobias, onde se hospedara, e referindo-lhe o fato, estranhou Liebman que eu não conhecesse seu "Efficacia e autorità della sentenza", que era posterior. Fui então conhecer esse livro que provocara a crítica severa e impiedosa de Carnelutti que, pela segunda vez, se dignava a descer do pedestal em que já se encontrava para ombrear-se com o jovem professor que já aprendera a respeitar. O debate que então travaram honra, pela elevação dos conceitos e a elegância e cavalheirismo dos contendores, a ciência jurídica italiana contemporânea.

Creio ter sido eu o primeiro estudioso de Direito Processual Civil a conhecer Liebman e freqüentar sua casa em São Paulo, afora Sebastiāo Soares de Faria, então Diretor da Faculdade de Direito. Liebman estivera na Argentina e no Uruguai e deplorava a ancianidade dos respectivos códigos de precesso civil, à luz dos quais não se sentia motivado para trabalhos doutrinários. Ansiava mudar-se para o Brasil, onde começara a vigorar o Código de Processo Civil de 1940 que, segundo Projeto de Pedro Baptista Martins, Francisco Campos, Ministro da Justiça de Getúlio Vargas, convertera em lei. Convidado por Campos, deteve-se rapidamente no Rio de Janeiro, onde fez conferências e conheceu Machado Guimarães, autor de "A instância e a relação processual", o único trabalho brasileiro da época à altura da ciência processual italiana e alemā.

Sebastião Soares de Faria conseguiu contratá-lo para a Faculdade de Direito. Chegando a São Paulo, Liebman proferiu imediatamente algumas conferências na Faculdade e, convidado por Di Giovanni, advogado italiano aqui residente, passou a ocupar uma sala em seu escritório. Sua residência, à Alameda Ministro Rocha Azevedo, deu-me a idéia do pseudônimo L.R. Azevedo, que adotei para uma série de seis artigos que publiquei no jornal "O Estado de S. Paulo". 
O convívio com Liebman foi utilíssimo. Ao preparar-me para o concurso à livre-docência, perdera tempo precioso lendo autores de segunda classe. Apesar de autodidata, percebera eu a enorme superioridade dos estudos italianos sobre os franceses e, sozinho, concluira que os maiores autores italianos eram Chiovenda, Carnelutti e Calamandrei. Não tivera, porém, a felicidade de encontrar alguém que me orientasse nas leituras de Direito Processual e de direito em geral. Trabalhos de história e de filosofia do direito, por exemplo. Liebman, discípulo de Scialoja e de Chiovenda, reputava fundamentais para a formação do processualista os estudos de Direito Romano, de direito intermédio, de direito germânico e de direito comum. Por não tê-lo conhecido senão depois de livre-docente, padeceu dessa falha minha formaçao de processualista. Já quanto aos de filosofia do direito, a presença e os conselhos de Liebman, no sentido de que não eram essenciais, serviram para que eu melhor aproveitasse meu tempo na preparação para o concurso à cátedra.

Liebman viera da Itália proscrito por ter alguns antepassados israelitas. Apesar de, nessa ocasião, ser o Governo brasileiro, por oportunismo, simpatizante do fascismo e, até, discreto perseguidor de judeus, Liebman foi aqui recebido de braços abertos. Era natural, como exilado político, que fosse antifascista. Apesar de suave e tolerante, Liebman não escondia essa posição. Muitos, por isso, julgavam-no adepto de regimes socialistas. Se, na verdade, não o era, compreende-se que os brasileiros, com o esquematismo próprio de povos imaturos, o classificassem como esquerdista.

Em setembro de 1961, quando se realizou, em São Paulo, o Congresso Internacional de Direito Processual Civil, reformou-se a Constituição brasileira e se instituiu aqui o regime parlamentar. Ouvi de Liebman, que já voltara à Itália e aqui viera como convidacio especial para o Congresso, uma observação curiosa. Pareceu-lhe que, com o Presidente Jango Goulart no Poder, instituído o regime parlamentar, devíamos registrar a data que, a seu ver, seria, no Brasil, aquilo que foi a tomada da Bastilha, na Europa, isto é, o marco divisório entre duas épocas. Na França, a ascenção da burguesia; no Brasil, a ascenção do proletariado.

Embora, como todo europeu, levemente paternalista em relação ao Brasil, deve-se, em sua honra, reconhecer e proclamar que poucos dispensaram, como ele, tanta consideração a estudos jurídicos brasileiros. Sempre, em seus livros e artigos, citou autores brasileiros. Em sua Rivista di Diritto Processual e muitas vezes na seç̧ão bibliográfica, recenseou livros brasileiros, e publicou sumários de legislação brasileira.

Em sua casa, na Alameda Ministro Rocha Azevedo, Liebman recebia aos sábados os estudiosos de Direito Processual Civil. Faziam parte do grupo Antonio Roggero, Benvindo Aires, Alfredo Buzaid, Plinio Cavalcanti de Albuquerque, Bruno Affonso de André e nós. Alguns tinham livros em preparação e 
levavam a Liebman capítulos que recebiam sua crítica. Às vezes, as discussões derivavam do direito para a política (principalmente no ano de 1945). Liebman cortesmente recusava participar do debate e trazia de novo à conversa os assuntos de Direito Processual Civil.

Liebman recebeu ofertas para patrocinar grandes causas. Sempre recusouas por entender que, advogando e competindo com advogados brasileiros, não estaria correspondendo à hospitalidade dos brasileiros. Limitava-se a dar pareceres. Nesse terreno, era particularmente escrupuloso. Por volta de 1941, contei-lhe que havia dado parecer a pedido de João Oliveira Filho, chefe do Departamento Jurídico de uma grande empresa paulista. Liebman, divergindo de minha conclusão, recusou-se a dar parecer. Seu ponto de vista foi mencionado na edição brasileira de seu "Eficácia e autoridade da sentença".

Por sua influência, os brasileiros são sempre convidados a colaborar nas coletâneas de estudos em honra de grandes autores italianos. Honrado com um desses convites, participei da homenagem a Francesco Carnelutti. Participei também, e comigo muitos autores brasileiros, da homenagem da mesma natureza prestado ao próprio Liebman.

Quem era Liebman por ocasião de sua chegada ao Brasil? Era um jovem estudioso italiano que, como há pouco dissemos, aos 23 anos, participara da coletânea em honra de Chiovenda e, aos 27, tivera a honra de merecer a consideração de Francesco Carnelutti nas polêmicas memoráveis que já comentamos. Quando elas ocorreram, Carnelutti já começava a ombrear com Chiovenda na liderança dos estudos processuais de todo o mundo. Sem embargo do tom condescendente do velho mestre, que provocou do moço a queixa ressentida de que não era levado "sul serio", este último passou imediatamente a ocupar lugar de primeira plana nas letras jurídicas italianas. Disputou a cátedra com Giovanni Cristofolini, morto prematuramente, a quem se devem talvez as mais profundas páginas que já se escreveram sobre a jurisdição voluntária.

Carnelutti, extremamente orgulhoso, que, sozinho entre seus contemporâneos, não se pejava de afirmar que não era discípulo de Vittorio Scialoja, jamais se dignaria de entrar em polêmica com quem quer que nāo tivesse méritos excepcionais. Liebman, embora, no fundo, fosse o mais fiel dos discípulos de Chiovenda, já ostentava, como vimos, pensamento próprio sobre inúmeras matérias, tais como: reconhecimento do pedido; competência em processos de jurisdição voluntária; caráter jurisdicional das decisōes proferidas em processos de verificação de créditos na falência; natureza jurídica do título executivo; natureza jurídica do processo de delibação de sentenças estrangeiras; nulidade do compromisso arbitral livre; invalidade do pacto "solve et repete"; e, sobretudo, sobre a natureza e a caracterização da coisa julgada, certamente o mais nobre dos assuntos de direito processual. 
Liebman nascera em Trieste, então pertencente ao Império Austro-Húngaro, que só se incorporaria ao Reino da Itália em 1918. Nunca, porém, apesar da ingratidão do governo de Mussolini, lhe ouvi uma palavra que se pudesse interpretar como renúncia à cidadania italiana. Serviu-lhe, no entanto, o local de seu nascimento, para dar-lhe o domínio da língua alemã, auxiliar precioso na formação de um grande jurisconsulto.

O comportamento de Liebman no Brasil teve tanta repercussão no mundo das letras jurídicas, que Niceto Alcalá Zamora y Castillo, grande mestre espanhol radicado no México, teve, na mais simpática das homenagens que se poderiam prestar ao Brasil e ao mestre italiano, a idéia nobre de aludir à existência de uma Escola de Direito Processual Paulista, cujos integrantes teriam sido Gabriel de Rezende Filho, Joaquim Canuto Mendes de Almeida, José Frederico Marques, Alfredo Buzaid e nós. O que teria levado esse bom Niceto a reunir em um só grupo esses nomes de tendências tão diversas? Por amor à verdade científica, sentimo-nos no dever de contestar o acerto da generosa sugestão.

Gabriel de Rezende Filho, como monografista, nada apresentara que, de longe, pudesse lembrar a doutrina de Liebman. Sua dissertação do primeiro concurso sobre a competência lembrava a lição bem aprendida de um bom aluno de João Monteiro. A outra, do segundo concurso, "Modificações objetivas e subjetivas da ação", já demonstrava a leitura de Chiovenda e Carnelutti. Mas, prescindindo da inegável verificação de que o próprio título de seu livro evidenciava seu distanciamento da nova escola, devemos lembrar que Gabriel era bem mais idoso do que Liebman e, ainda, que mesmo seu compêndio, que veio a ser publicado depois, já estava em embrião em suas bem compiladas aulas taquigrafadas.

Joaquim Canuto, contestador inteligente e combativo, já publicara seus dois livros. Tendo sempre presente o pensamento do Tio João Mendes Junior, inclinava-se ("horresco referens") para o que, na época, um fátuo e presumido civilista chamava de carrousel carneluttiano. José Frederico Marques ultrapassava de muito os limites de uma escola de direito processual: enciclopédico do direito, constitucionalista, penalista, administrativista, fiscalista e, afinal, processualista, pouco ficou a dever ao pensamento do grande Liebman.

Alfredo Buzaid já escrevera sua "Ação Declaratória" que pouco depois seria editada. Este último e nós próprios fomos, em suma, os verdadeirios discípulos do mestre.

Buzaid, único autor do Código de Processo Civil Brasileiro, em sua modéstia, viria a proclamar trinta e cinco anos depois: "Esse código é um monumento imperecível de glória a Liebman". 
Nós, aprendendo com Liebman, a nos corrigir os erros e orientar nossos canhestros estudos sobre a ação rescisória que, a princípio, supúnhamos ser mera declaratória de nulidade e que, depois, aberto o caminho pelo mestre, viemos a filiar à "querela nullitatis" do direito medieval.

Embora nao mencionado por Niceto Alcalá Zamora, devemos lembrar que Pedro Baptista Martins, responsável pela reforma processual de 1940, ao escrever seus autênticos comentários sobre o Código de Processo Civil, lamentavase de não ter conhecido antes o "Eficácia e autoridade da sentença", para ter a oportunidade de aperfeiçoar seu Projeto. Por ocasião de sua morte prematura, em 1950, a Rivista di Diritto Processuale, publicou, assinado por Liebman, elogioso necrológio.

Foram então só esses dos discípulos brasileiros de Liebman? Parece pouco para seis anos de permanência no Brasil. Que engano! Vede, por um momento, sem nos afastarmos muito do objeto desta alocução, os desdobramentos desse grupo inicial.

No Rio Grande do Sul, Galeno Lacerda e Alcides de Mendonça Lima; no Paraná, Egas Monis de Aragão e Ary Florêncio Guimarães; em Minas, Celso Agricola Barbi e José Olympio de Castro, no Rio, Barbosa Moreira e Eliezer Rosa; na Bahia, Calmon de Passos. E, por último, São Paulo.

Aqui, em primeiro lugar Celso Neves, esse mestre de direito e da fidalguia, com seu clássico "Arrematação de Real a Real" e seu profundo e erudito estudo sobre a coisa julgada. Depois, Moacyr Lobo da Costa que, com proficiência e maestria, tratou de dois temas caros a Liebman: o, reconhecimento do pedido e a "querela nullitatis". Ada Pellegrini Grinover, com seus magistrais estudos sobre "Liberdades Públicas e Processo Penal"; Eficácia e autoridade da Sentença Penal; Condições da ação Penal; Ação declaratória incidental; Direito de Ação; o conjunto de conferências no Centro de Aperfeiçoamento Jurídico e tantos outros.

Cândido Rangel Dinamarco, com seus" estudos sobre "Fundamentos do Processo Civil Moderno"; Litisconsórcio; suas conferências sobre o novo Código de Processo Civil; a Execução na Teoria Geral do Processo Civil; a Instrumentalidade do Processo.

Antonio Carlos de Araújo Cintra com suas monografias sobre o Litisconsórcio Unitário e os limites objetivos da apelação civil.

Estes três últimos, responsáveis pela consagradíssima Teoria Geral do Processo, que escreveram em conjunto. 
José Ignácio Botelho de Mesquita, com seus "A autoridade da coisa julgada e a imutabilidade da motivação da sentença"; "A causa 'petendi' nas ações reivindicatórias"; "Da propositura da ação de mandato de segurança"; "Da liquidez suficiente para requerer a falência" e "Da Ação Civil"; Vicente Greco Filho, com seu "Da execução contra a Fazenda Pública"; Kazuo Watanabe, com seu "Juizado de Pequenas Causas"; José Roberto Franco da Fonseca, com sua monografia sobre o processo falimentar; Tomás Pará Filho, com seus clássicos estudos sobre a conexão de causas e a sentença constitutiva.

Fora desta escola, Waldemar Mariz de Oliveira Junior e Arruda Alvim, na Universidade Pontifícia; José Xavier de Albuquerque e Sidney Sanches, no Supremo Tribunal Federal.

Esses e tantos outros foram os discípulos de Liebman no Brasil.

Terminada a guerra, Liebman voltou à Europa. Seu nobre coração lhe inspirou as primeiras palavras aos colegas italianos. Comemorou, em emocionante evocação, o décimo aniversário da morte de Giuseppe Chiovenda. Seu "Processo de Execução", escrito em português, foi objeto de recensão na "Rivista di Diritto Processuale". Carnelutti, com quem mantivera ásperas polêmicas, recebe-o de braços abertos: que um de nossos melhores processualistas tenha sido constrangido a buscar refúgio na América Latina e lá tenha encontrado meio de ensinar direito e publicado um livro como este que faz honra à ciência italiana, é o caso de repetir ainda uma vez "a quelque chose malheur est bon".

Seu primeiro artigo doutrinário na Itália é grito de alerta contra o retorno de disposições processuais aos códigos civis. "Se o caminho percorrido neste meio século se pode resumir simbolicamente na passagem do procedimento ao direito processual, fique bem claro que o perigo contra o qual nos insurgimos é o de concluir o ciclo e o destino da ciència do processo com uma rápida viagem de retorno ao ponto de partida". Se o mestre tivesse permanecido no Brasil talvez tivesse evitado que nosso Projeto de Código Civil em tramitação no Congresso Nacional incidisse no mesmo erro ao praticamente reproduzir uma vintena de artigos sobre a prova vindos do Código Civil vigente.

A morte de James Goldschmidt levou-o a análise e crítica da teoria da situação jurídica processual. Liebman manteve-se fiel à doutrina clássica da relaçảo jurídica processual de Oskar Von Bülow que data de 1868. Mas a apresentação da doutrina de Goldschmidt e as considerações críticas que em torno dela desenvolveu constituem leitura indispersável para se compreenderem os originais de Goldschmidt. Lembro-me bem o quanto me valeram nesse sentido as aulas particulares que, com o maior desprendimento, o mestre nos dava todas as semanas em sua casa da Alameda Ministro Rocha Azevedo. 
Em 1952, já professor ordinário na Universidade de Pavia, seu nome aparece, pela primeira vez, ao lado de Virgilio Andrioli, como co-diretores da Rivista di Diritto Processuale, logo abaixo de Carnelutti e Calamandrei.

No ano anterior, professor ordinário de Turim, presta sua última homenagem ao país que o abrigara durante o exílio. Publica, nos "Estudos em honra de Enrico Redenti", "Istituti del Diritto Comune nel Processo Civile Brasiliano". E enumera-os: as ações de jactância; a propositura de ação; as exceções dilatórias; a apelação de terceiro; o benefício comum da apelação; a "querela nullitatis"; o processo executivo. Antes de Liebman, pouco se falava, no Brasil, em direito comum como fonte do direito objetivo. Depois dele, tornou-se corrente em estudos brasileiros. Poder-se-á contestar, em alguns pontos, a opinião do mestre. Quanto aos juizos de jactância, por exemplo. Dificilmente se pode afirmar que a ação meramente declaratória brasileira a eles se filia. $\mathrm{O}$ mesmo quanto à ação rescisória dos julgados. A "querela nullitatis" vinha do século XII. Se as Ordenações Afonsinas, do século XV, não lhe adotaram o nome, é razoável supor que tivessem preferido manter o instituto romano e medieval da nulidada absoluta do julgado, do que resultaria o caráter meramente declaratório e não constitutivo da decisão rescisória.

Esse trabalho original de pesquisa sobre a origem remota dos institutos processuais brasileiros seria suficiente para justificar a generosa e simpática sugestão de Niceto Alcalá Zamora y Castillho da existência de uma escola paulista do direito processual? Parece-nos que não. No entanto, nós a aceitamos como homenagem devida a Liebman. Porque Liebman, com sua forte personalidade, transplantou da Itália para o Brasil o espírito universitário, feito mais de modéstia e humildade do que de jactância e pretensão. Porque evidenciou, com o exemplo de sua preferência, que o direito processual deixara de ser disciplina ancilar do direito material. Porque aperfeiçoou o método de trabalho dos estudiosos brasileiros. E, acima de tudo, porque rehabilitou e enobreceu, como ninguém, a tão malsinada e esquecida profissão do magistério. 